Article

\title{
Thermal and Daylighting Performance of Energy-Efficient Windows in Highly Glazed Residential Buildings: Case Study in Korea
}

\section{Chang Heon Cheong ${ }^{1, *}$, Taeyeon Kim $^{2}$ and Seung-Bok Leigh ${ }^{2, *}$}

1 Department of Architectural Engineering, Gyeongnam National University of Science and Technology, 33 Donjinro, Jinju 660-758, South Korea

2 Department of Architectural Engineering, Yonsei University, 50 Yonsei-ro, Seodaemun-gu, Seoul 120-749, South Korea; E-Mail: tkim@yonsei.ac.kr

* Authors to whom correspondence should be addressed; E-Mails: Changheon@gntech.ac.kr (C.H.C.); Sbleigh@yonsei.ac.kr (S.-B.L.); Tel.: +82-55-751-3676 (C.H.C.); +82-2-2123-5782 (S.-B.L.).

External Editor: Marc A. Rosen

Received: 5 August 2014; in revised form: 17 October 2014 / Accepted: 17 October 2014 / Published: 23 October 2014

\begin{abstract}
Cooling load in highly glazed residential building can be excessively large due to uncontrolled solar energy entering the indoor space. This study focuses on the cooling load reduction and changes in the daylighting properties via the application of a double window system (DWS) with shading with various surface reflectivities in highly glazed residential buildings. Evaluation of thermal and daylighting performances is carried out using simulation tools. The reductions in cooling load and energy cost through the use of DWS are evaluated through a comparative simulation considering conventional windows: a single window and a double window. Three variables of window types, natural ventilation, and shading reflectivity are reflected in the study. According to our results, implementation of DWS reduced cooling load by $43 \%-61 \%$. Electricity cost during the cooling period was reduced by a maximum of $24 \%$. However, a shading device setting that prioritizes effective cooling load reduction can greatly decrease the daylighting factor and luminance level of indoor space. A DWS implementing shading device with highly reflective at all surfaces is appropriate option for the more comfortable thermal and visual environment, while a shading device with low reflectivity at rear of the surface can contribute an additional $4 \%$ cooling load reduction.
\end{abstract}


Keywords: double window system; residential building; cooling load; cooling energy consumption; visual environment

\section{Introduction}

The form and construction of facade systems have a strong influence on both the energy consumption of a building and the comfort level of its occupants. A double window system (DWS) is an energy-efficient envelope system in which a cavity is placed between the inner and outer layers to provide natural ventilation, solar radiation control, and enhanced insulation [1-7]. The DWS is a box-type double-skin facade that is also effective in reducing heating and cooling energy consumption [8-11]. In addition, buildings with double-skin facades offer better thermal comfort in the winter and lower thermal amplitude during the summer [10]. Compared to single-skin facades, the double-skin facades used in South Korea reduce energy consumption during the hot and temperate seasons without any additional energy input. During the cold season, they require proper operation of their shading and natural ventilation devices to successfully reduce energy consumption $[12,13]$. The operation of the double-skin facade can influence the energy performance of the buildings [14]. The greenhouse effect in the cavity in the east and west facades may increase heat stress to the internal space, thus, appropriate natural ventilation control is required [15]. The results of previous investigations indicate that the application of natural cooling strategies is important in buildings with double skins [12-16].

The climate in Korea is characterized by hot, humid summers and cold, dry winters. Such a climate pattern results in drastic variations in heating and cooling energy consumption. Generally, in residential buildings, the winter heating load has always outweighed the summer cooling load. Nowadays, however, the increase in the cooling load in high-rise residential buildings with highly glazed curtain wall systems is becoming a major problem. The conventional curtain wall systems, which are often adopted for highly glazed residential buildings, have only small operable windows to provide natural ventilation [17]. In addition, the internal shading devices that are usually provided, regardless of the type of building, present many difficulties related to solar radiation control. Together, these two factors contribute to the increased cooling energy consumption of highly glazed residential buildings. Consequently, there is a greater demand for cooling in the summer, leading to higher electricity costs with a graduated tariff system. On the other hand, double-skin facades are equipped with various shading devices in the inter-cavity for solar protection $[18,19]$ and to improve the visual environment and reduce the cooling energy [20-22]. The reduction of solar radiation entering the indoor space may contribute to cooling load reduction, but daylighting performance can be degraded. To satisfy the requirement of cooling load reduction and a comfortable daylighting environment, selection of an appropriate shading device should be considered.

This study focuses on the cooling load reduction effect and daylighting performance of the DWS with a shading device that has selective surface reflectivity that operates a cooling energy reduction focused mode in highly glazed residential buildings. To evaluate the performance of the DWS, a comparative energy simulation is performed. Single window (SW) and double window (DW) systems are selected as the conventional window systems. 


\section{Method}

Research was performed in the following sequence of steps: establishing a base model with an SW, validation of simulation with actual energy consumption data, a comparative study on energy consumption, and finally daylighting analysis. An energy simulation was performed using the ESP-r energy simulation tool. To confirm the feasibility of the simulation results, a baseline model was established. The base model reflects the thermal properties of existing highly glazed residential buildings. The simulated energy consumption of the base model was compared with the actual monthly energy consumption data of the target building. The comparative study focused on reductions in cooling energy consumption and electricity cost resulting from the application of the DWS, with variations in the ventilation mode and shading surface reflectivity.

The evaluation of the daylighting performance by the DWS and shading device uses the daylighting factor (DF), illumination distribution, useful daylight index (UDI) and absolute glare of the indoor space. The DF is represented by the ratio of the illumination level of a specific indoor point and the outdoor horizontal illumination level. Illumination distributions by each window and shading device at the summer solstice are also compared. UDI represents the usefulness of the daylight. It uses three illumination range: 0-100 lx, 100-2000 lx and over $2000 \mathrm{~lx}$. Absolute glare is determined by the luminance value of the light source. The luminance values needs to be kept below $1000 \mathrm{~cd} / \mathrm{m}^{2}$ in the normal visual field and maintained below $2000 \mathrm{~cd} / \mathrm{m}^{2}$ according to Swedish National Board for Industrial and Technical Development (NUTEK) guideline [23].

Recently, simulation tools are being considered useful for daylighting analysis. Daylighting simulation is also performed to evaluate the indoor visual environment. For the analysis of the daylighting performance by the DWS and the shading device with various reflectivities, the Radiance program is used. Radiance is a daylighting simulation program that uses the ray-tracing method and operates as a plug-in of Ecotect [24,25]. DF and absolute glare are evaluated by radiance. Daysim is also available as a plug-in of Ecotect, and used for the UDI evaluation. Ecotect has been used for simulation modeling and visualization. The daylighting factor and the illuminance of the living room are evaluated using these programs.

\section{Window System}

A DWS is a box-type double-skin facade unit with an intermediate cavity and shading. Figure 1 illustrates a basic DWS unit and Figure 2 shows conventional window units. An SW forms part of a conventional curtain wall system that uses outward-opening windows, a pair of tinted glass panes, and an internal shading device. Tinted glass is generally adopted to reduce solar heat transmission in highly glazed buildings. Tinted glass in an SW unit reduces solar transmission but absorbs large amounts of solar energy that is subsequently transferred back to the indoor space via convection and long-wave radiation. Some of the transmitted solar radiation is reflected by the internal shading device. However, the high absorption of the glazing system recaptures the reflected solar radiation, thus, reducing the efficacy of the shading device. SW units are designed to provide natural ventilation. However, they allow a small amount of airflow through the restricted operable area. A conventional DW consists of two double-paned windows and an internal shading device. This type of window system is widely used in 
Korea to increase the thermal resistance of building skins and, therefore, reduce heat loss and the risk of condensation during the heating season. In highly glazed buildings using curtain wall systems, an additional sliding internal window system can be installed by the occupants to form a DW. The DWS consists of two double-paned windows and a shading device in the intermediate space between the external and internal windows. The external curtain wall system has an outward-opening window that can regulate natural ventilation, and the shading provides better solar control in the intermediate space. Coloring can be used to control surface reflectivity, as well as shading devices made of aluminum slats. In this study, two types of shading devices are considered: a shading device with high reflectivity (84\%) on both surfaces, and a shading device with a highly reflective (84\%) surface outward and a low reflective (10\%) surface inward. The shading device with different surface reflectivities is intended to absorb solar energy and exhaust the heat energy via cavity ventilation. This approach decreases the amount of solar radiation ultimately entering the room. The external window and the shading device of a DWS act like a barrier that protects the internal window system against the hot outdoor environment during the cooling season. The DWS considered in this investigation adopts an external "parallel-out" window, whereby the entire window opens parallel to the facade, and there is an internal window that tilts and turns to open. The external window permits the maximum possible airflow, and the internal window can be used to regulate the airflow. In a DWS, shading devices are installed in the intermediate cavity between the external and internal windows. Solar radiation is blocked by the shading device, and any heat absorbed by the shade can be exhausted outdoors by ventilating the cavity space.

Figure 1. Conceptual geometry of DWS.

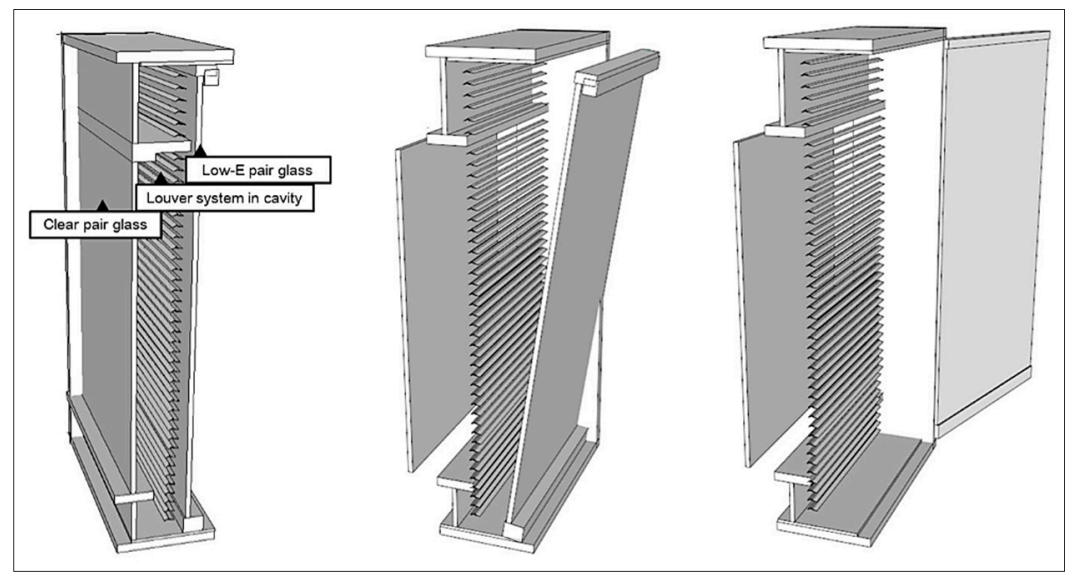

Figure 2. Conventional window systems. (a) Single window (SW); (b) Double window (DW).

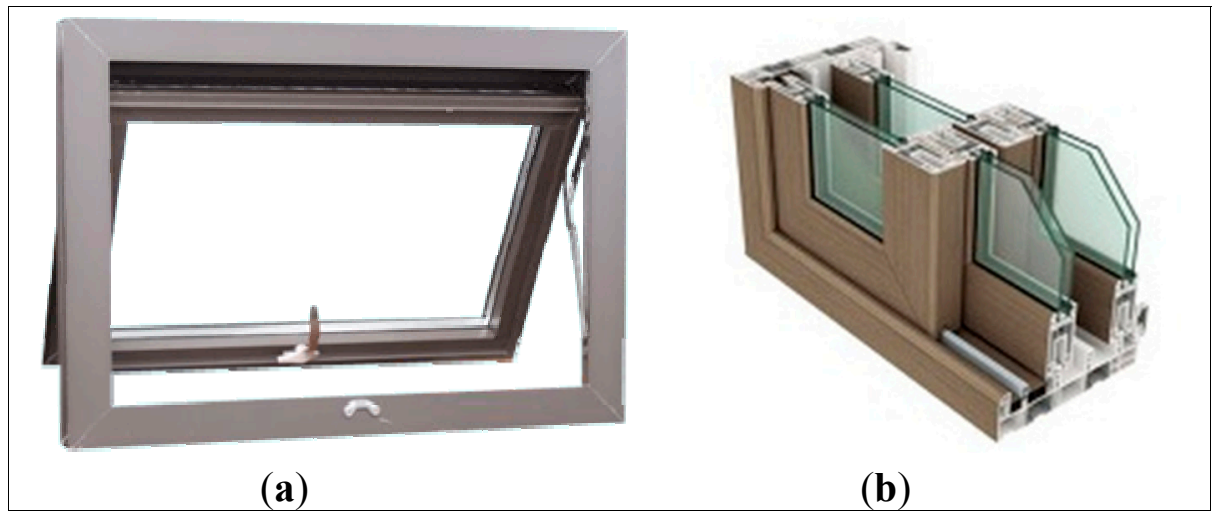




\section{Baseline Model for Energy Simulation}

\subsection{Target Building}

The comparative study used a case study that evaluated cooling load reduction through the use of the DWS. As the base model, a residential building in Seoul with a highly glazed facade system was selected (shown in Figure 3). This building adopts a curtain wall system with tinted glass and small operable windows, as depicted in Figure 4. In addition, internal shading devices are used for solar control. Package air-conditioning (PAC) systems are used to cool individual residences. The building's floor plan makes cross-ventilation impractical. These features result in poorer natural ventilation performance than in conventional residential buildings in which cross-ventilation is possible. Regarding the window system of the target building, one or two outward-opening windows, each measuring $0.84 \mathrm{~m} \times 1.7 \mathrm{~m}$, are installed in each room. In a typical residential building, a sliding-window system is installed in the living room to provide ample amount of ventilation for the indoor space. In this building, however, the outward-opening windows provide relatively limited natural ventilation. The original floor plan of the target building features balconies in the perimeter zone. Many occupants, however, removed this space in order to increase the indoor living area. This type of renovation, in which the thermal buffer is removed, often results in the building consuming more energy for cooling and heating. To examine a worst-case energy consumption scenario, a residential unit without a balcony is selected as the base model for energy analysis and further visual analysis.

Figure 3. Target building.

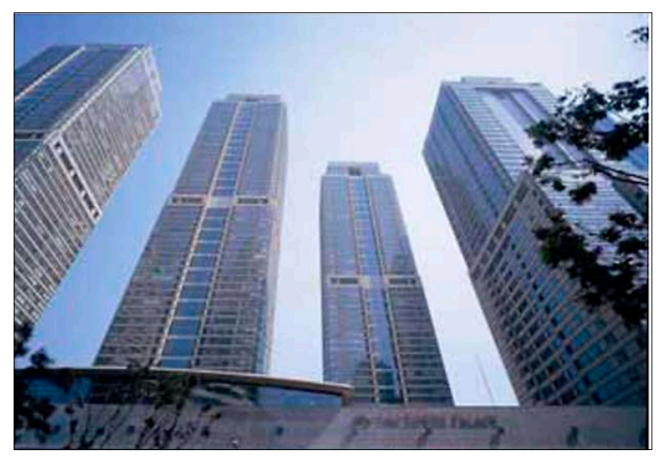

Figure 4. Conventional window system.

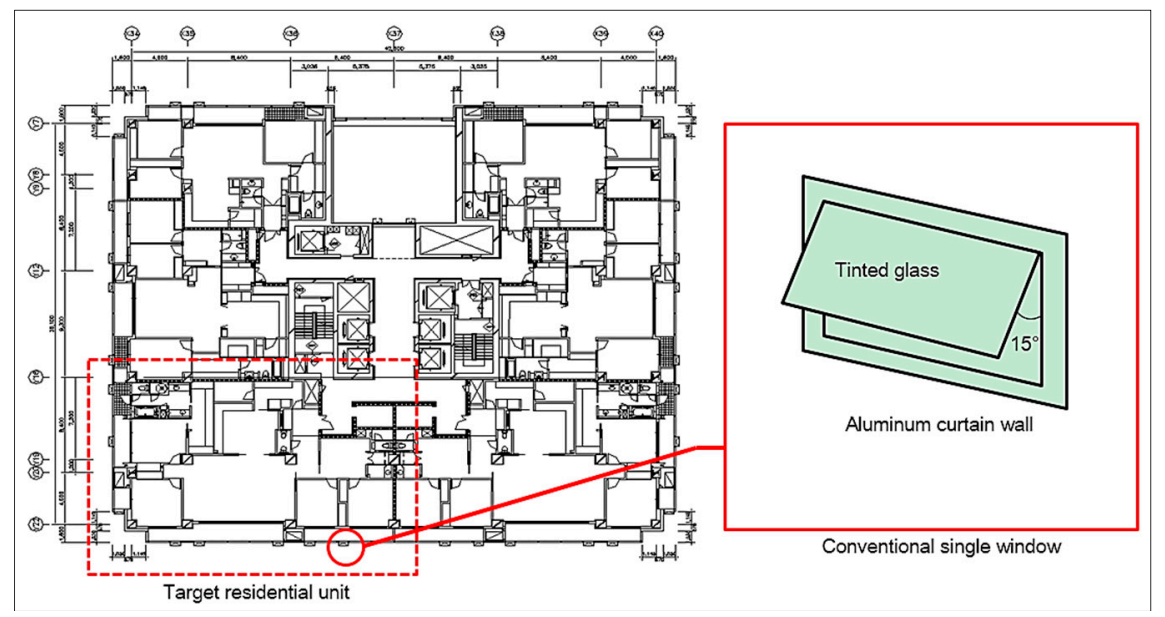




\subsection{Simulation Modeling}

To establish a base model for the comparative study, we performed an energy analysis on the target residential unit by using the ESP-r energy simulation package. Figure 5 illustrates the simulation model. An energy simulation was performed using the actual thermal properties of the construction used in the target building. Tables 1 and 2 list the thermal properties of the wall construction and glazing system used in the simulation. Tinted glass panes are used in the window system. An internal horizontal-shading device, set at an angle of $45^{\circ}$, was used during the entire cooling period (May to October). Cooling was provided solely by a PAC system. No natural ventilation was allowed, but a minimum amount of ventilation of $0.7 \mathrm{ACH}$ was provided by a mechanical ventilator. The evaluated cooling load of target unit was converted to end-use energy by Equation (1). The heating energy was provided by a district heat supplier with a 5\% heat loss. The cooling device's coefficient of performance (COP) was set to 3 . The climate data used are the default data from Seoul supplied by the ESP-r simulation tool. Figure 6 illustrates the internal heat-gain profile.

$$
\text { Monthly cooling energy (simulation) }=\frac{\text { Cooling load }}{C O P \text { of } P A C}
$$

Figure 5. Simulation model for baseline building.

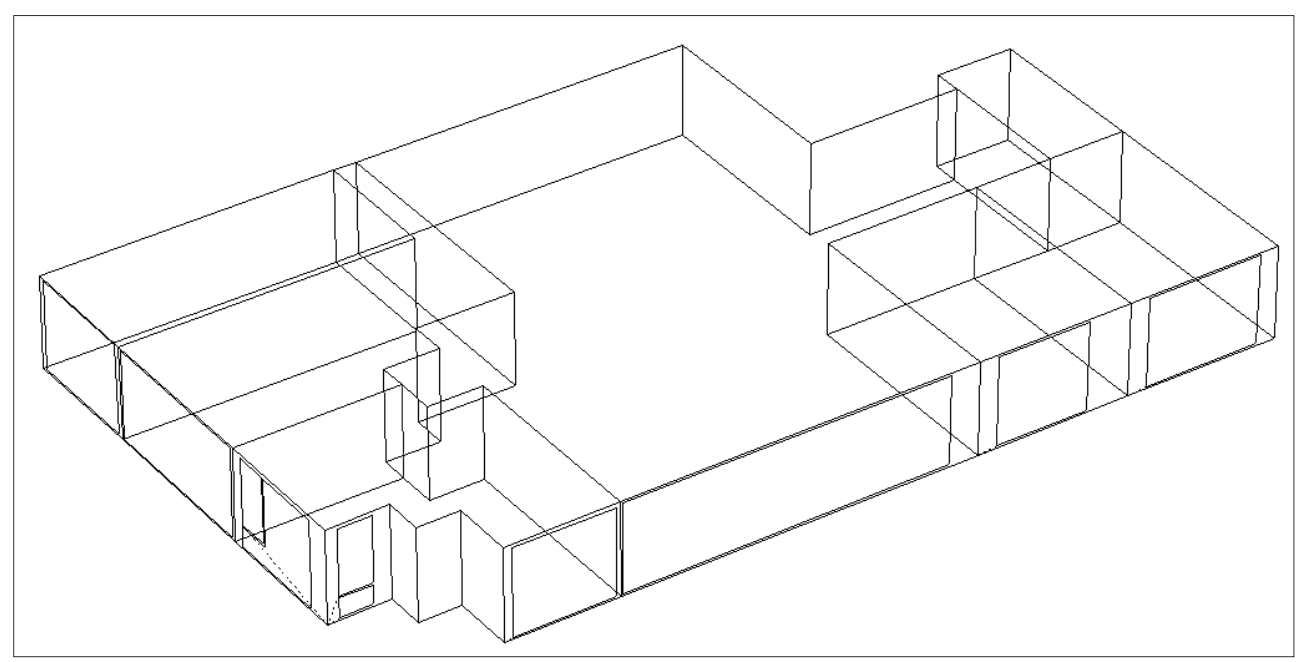

Table 1. Thermal properties of the wall construction.

\begin{tabular}{cc}
\hline Composition & U-factor \\
\hline External wall & $0.47 \mathrm{~W} / \mathrm{m}^{2} \mathrm{~K}$ \\
Internal wall & $0.6 \mathrm{~W} / \mathrm{m}^{2} \mathrm{~K}$ \\
\hline
\end{tabular}

Table 2. Thermal properties of the glazing system.

\begin{tabular}{cc}
\hline Component & Properties \\
\hline U-factor & $2.7 \mathrm{~W} / \mathrm{m}^{2} \mathrm{~K}-\mathrm{Al}$ frame \\
Solar transmittance & 0.236 \\
Shading device & Internal shading device \\
\hline
\end{tabular}


Figure 6. Internal heat gain. (a) Lighting-room; (b) Lighting-living room; (c) Appliance (room); (d) Appliance (living room).

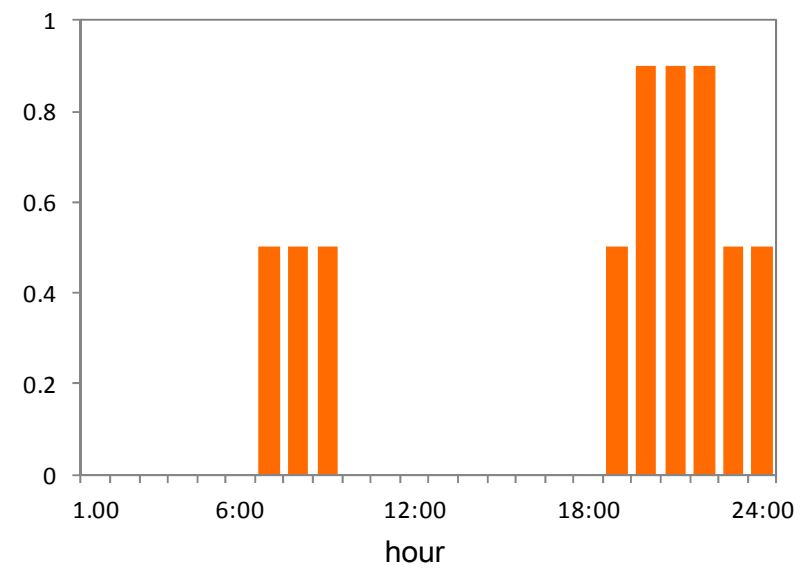

(a)

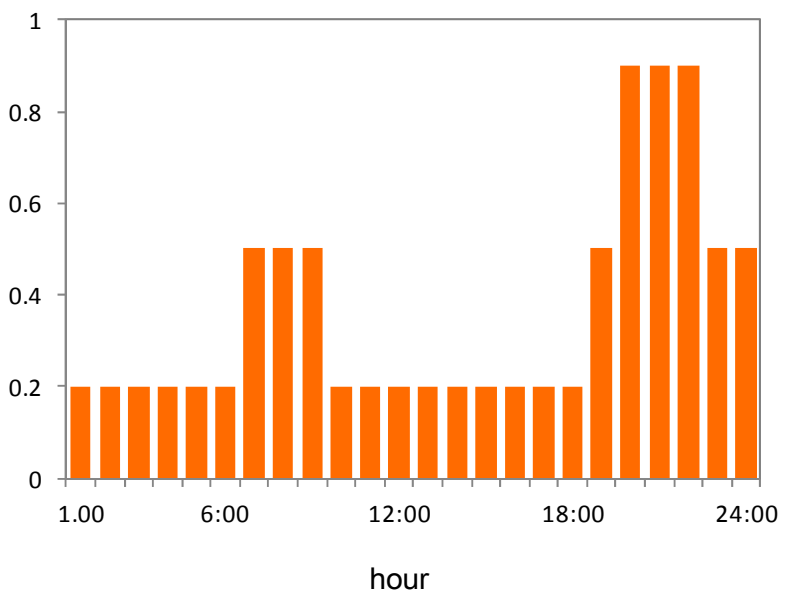

(c)

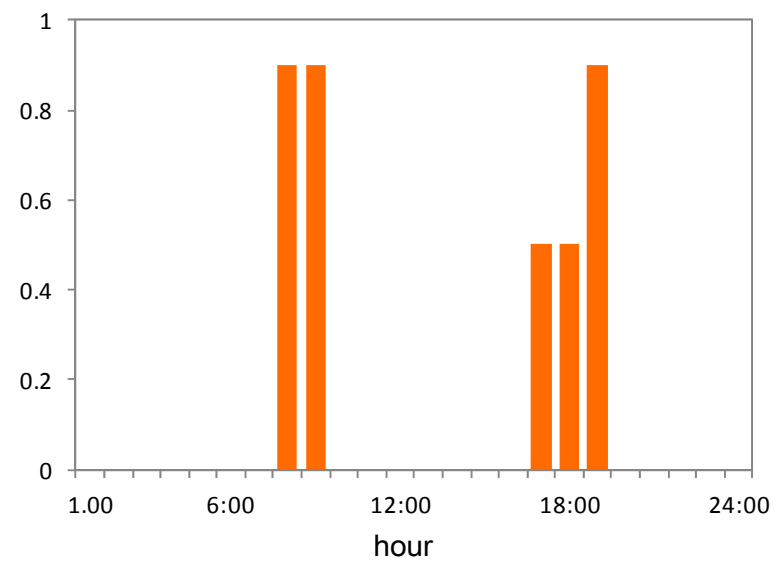

(b)

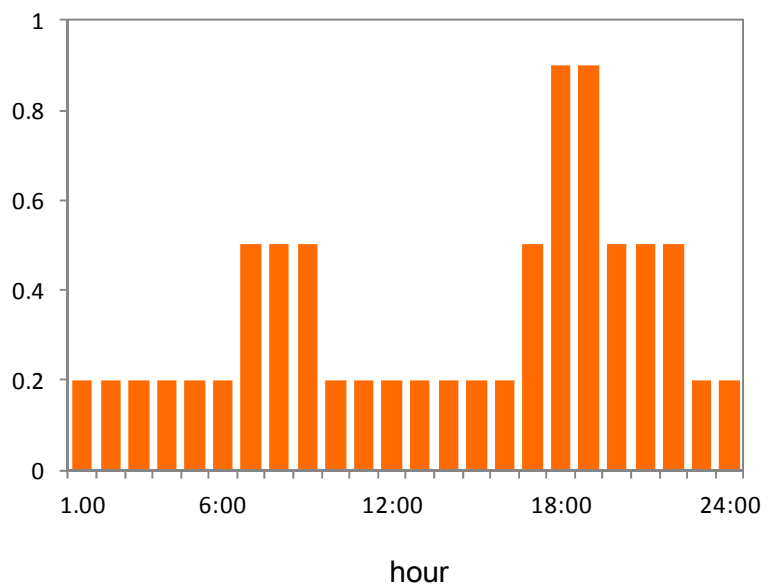

(d)

\subsection{Results}

In this section, the simulated energy consumption and the actual energy consumption are compared. Actual energy consumption data were obtained from the energy supplier. The energy consumption of the target residential unit is not available, and the averaged energy consumption of the entire residence was used. In addition, cooling energy consumption (electricity) is calculated by Equation (2). The monthly base energy consumption refers to the monthly minimum electricity consumption used for lighting and plug load.

$$
\begin{aligned}
& \text { Monthly cooling energy (measued) } \\
& \qquad=\text { monthly consumption - monthly base consumption }
\end{aligned}
$$

Figure 7 and Table 3 provide validation of the results, comparing the actual and simulated energy consumption. The pattern of simulated results is in good agreement with the actual energy consumption data, despite the degree of uncertainty in using bulk-type energy consumption data and the difficulties in fine-tuning the simulation model. 
Figure 7. Comparison between actual energy consumption and simulated results.

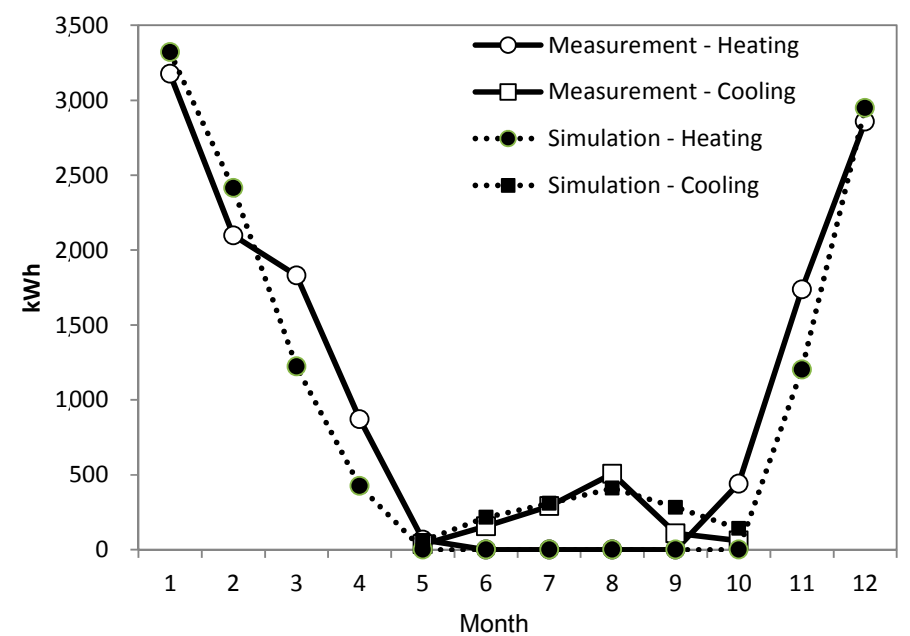

Table 3. Comparison of simulated and measured end-use energy consumption.

\begin{tabular}{ccccc}
\hline \multirow{2}{*}{ Month } & \multicolumn{2}{c}{ Measurement (k Wh) } & \multicolumn{2}{c}{ Simulation $(\mathbf{k}$ Wh) } \\
\cline { 2 - 5 } & Heating & Cooling & Heating & Cooling \\
\hline January & 3176 & & 3321 & \\
February & 2098 & & 2414 & \\
March & 1831 & & 1223 & \\
April & 872 & & 425 & \\
May & 67 & 35 & & 61 \\
June & & 157 & & 216 \\
July & & 290 & & 309 \\
August & & 507 & & 410 \\
September & & 109 & & 283 \\
October & 441 & 61 & & 141 \\
November & 1738 & & 1203 & \\
December & 2858 & & 2948 & \\
Sum & 13,081 & 1159 & 11,534 & 1420 \\
Difference & & & $11.8 \%$ & $22.6 \%$ \\
\hline
\end{tabular}

\section{Energy Simulations}

\subsection{Simulation Cases}

A comparison of the energy performance of the DWS and conventional windows was performed via an energy simulation. Variations in window type, natural ventilation, and surface reflectivity of the shading device installed in the DWS were considered. Tables 4 and 5 list the detailed thermal properties of the glazing system, together with the simulation cases. Figure 8 illustrates the DWS implemented simulation model. The SW and DW implemented model used the geometry of the baseline simulation model shown in Figure 5. An SW system was originally adopted for the target residential building. An SW system is a conventional curtain wall system with a low thermal resistance, whereby the U-factor of the window is generally determined by its aluminum frame. A DW system with a two-layer window arrangement and an internal shading device was also considered as a conventional window system. DW 
systems often use PVC frames and low-E glass for the panes of the internal window to increase thermal resistance. The DWS is proposed as an alternative window system. A DWS is a double-layer window system integrated into a curtain wall. An aluminum frame is used throughout the system, and low-E glass panes are used for the internal window system in order to compensate for the low thermal resistance of the aluminum frame. To evaluate the effect that the reflectivity of the shading device integrated into the DWS has on the cooling load, different simulation cases were incorporated into the overall simulation. DWS-1 adopts a shading device with a high reflectivity (84\%) on both of its surfaces. DWS-2, on the other hand, has a shading device whereby the reflectivity of the surface facing outward is high (84\%) and that of the inward surface is low (10\%). The shading devices were all of the horizontal type and set at an angle of $45^{\circ}$. The shading device was used constantly during the entire cooling period (May to October). The shading device modeling method was based on the complex fenestration construction model of ESP-r [26]. The entire airflow network was modeled for the cavity of the DWS and every room in the target building to evaluate the performance of natural ventilation. An AFN model that reflects the geometric properties of the window systems is established. The airflow model adopted the standard orifice model. This model is expressed by Equation (3), Table 5 shows the operable areas of window systems. SW and DW have identical operable area. Operable area of internal window can be controlled by the occupants in consideration of the indoor and outdoor air temperatures.

$$
\mathrm{Q}=\mathrm{C}_{\mathrm{d}} \cdot \mathrm{A} \cdot\left(2 \cdot \frac{|\mathrm{P}|}{\rho}\right)^{\frac{1}{2}}
$$

Q: Mass flow (kg/s); Cd: Discharge coefficient; $\rho$ : Fluid density; A: Area of opening.

Table 4. Simulation cases for comparative study.

\begin{tabular}{cccc}
\hline Case & Window & $\begin{array}{c}\text { Shading device } \\
\text { (outward reflectivity/inward reflectivity) }\end{array}$ & Ventilation mode \\
\hline Case 1 & SW & Internal shading device $(84 \% / 84 \%)$ & \\
Case 2 & DW & Internal shading device $(84 \% / 84 \%)$ & Minimum ventilation \\
Case 3 & DWS-1 & Shading in cavity $(84 \% / 84 \%)$ & mode $(0.7$ ACH) \\
Case 4 & DWS-2 & Shading in cavity $(84 \% / 10 \%)$ & \\
\hline Case 5 & SW & Internal shading device $(84 \% / 84 \%)$ & Natural ventilation + \\
Case 6 & DW & Internal shading device $(84 \% / 84 \%)$ & Minimum ventilation \\
Case 7 & DWS-1 & Shading in cavity $(84 \% / 84 \%)$ & mode $(0.7$ ACH) \\
Case 8 & DWS-2 & Shading in cavity $(84 \% / 10 \%)$ & \\
\hline
\end{tabular}

Figure 8. Simulation model for the DWS implemented model.

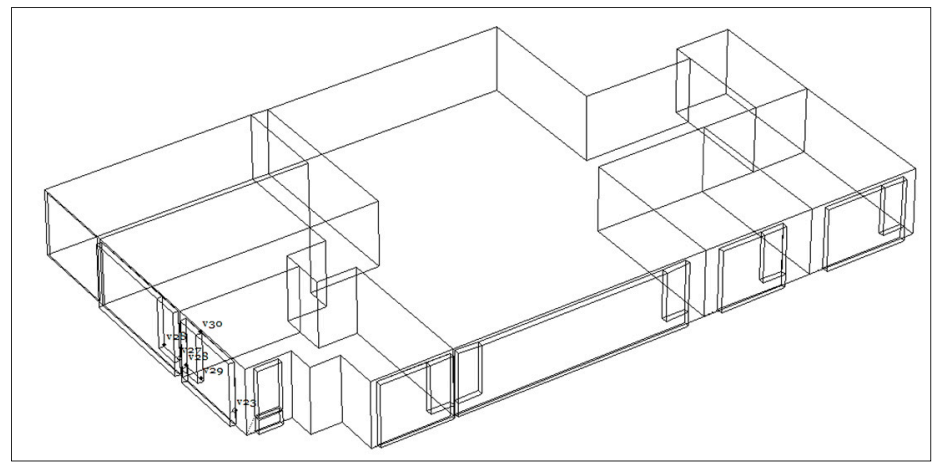


Table 5. Thermal properties of the window system.

\begin{tabular}{ll}
\hline Type & Properties of window system \\
\hline $\mathrm{SW}$ & - Glazing type: tinted glass panes \\
& - U-factor: external window $\left(2.7 \mathrm{~W} / \mathrm{m}^{2} \mathrm{~K}-\mathrm{Al}\right.$ frame $)$ \\
& - Solar transmission: 0.236 \\
& - Operable area: $0.62 \mathrm{~m}^{2}\left(\mathrm{C}_{\mathrm{d}}: 0.13\right)$ \\
\hline $\mathrm{DW}$ & - Glazing type: clear glass panes + low-E glass panes \\
& - U-factor: internal window $\left(1.2 \mathrm{~W} / \mathrm{m}^{2} \mathrm{~K}-\mathrm{PVC}\right.$ frame $)$ \\
& external window $\left(2.7 \mathrm{~W} / \mathrm{m}^{2} \mathrm{~K}-\mathrm{Al}\right.$ frame $)$ \\
& - Solar transmission: 0.266 \\
& - Operable area: $0.62 \mathrm{~m}^{2}\left(\mathrm{C}_{\mathrm{d}}: 0.13\right)$ \\
\hline DWS & - Glazing type: clear glass panes + low-E glass panes \\
& - U-factor: internal window $\left(2.4 \mathrm{~W} / \mathrm{m}^{2} \mathrm{~K}-\mathrm{Al}\right.$ frame) \\
& external window $\left(2.7 \mathrm{~W} / \mathrm{m}^{2} \mathrm{~K}-\mathrm{Al}\right.$ frame $)$ \\
& - Solar transmission: 0.266 \\
& - Operable area $1($ External window-cavity space): \\
& Horizontal opening: $0.17 \mathrm{~m}^{2}\left(\mathrm{C}_{\mathrm{d}}: 0.64\right)$ \\
& Vertical opening: $0.36 \mathrm{~m}^{2}\left(\mathrm{C}_{\mathrm{d}}: 0.24\right)$ \\
& - Operable area 2 (Internal window): \\
& Fully opened condition: $1.28 \mathrm{~m}^{2}\left(\mathrm{C}_{\mathrm{d}}: 0.64\right)$ \\
& Partially opened condition: $0.60 \mathrm{~m}{ }^{2}\left(\mathrm{C}_{\mathrm{d}}: 0.64\right)$
\end{tabular}

\subsection{Natural Ventilation Strategy}

Natural ventilation is an important factor in reducing the amount of energy needed for cooling, such that a suitable ventilation strategy is established [12-16]. During cooling period, especially in hot-humid region, elevated air movement and sufficient natural air change rate can be desirable to ensure indoor thermal comfort by natural ventilation $[27,28]$. At the same time, excessively high indoor airflow speeds must be prevented when the outdoor wind is strong. To establish a natural ventilation strategy for the DWS, three major factors were considered: wind speed, window control according to the indoor/outdoor temperature, and window closing when natural ventilation is not sufficient to provide an acceptable level of comfort. With regard to the outdoor wind speed, when it is appropriate for natural ventilation, an internal window can be partially opened (appropriate ventilation mode) or fully opened (maximum ventilation mode). It is assumed that basically the window is fully opened, and the partially opened mode is actuated when the outdoor wind speed reaches $4 \mathrm{~m} / \mathrm{s}$. The external and internal windows are closed when the outdoor wind speed reaches $6 \mathrm{~m} / \mathrm{s}$ [29]. If natural ventilation is not possible, the internal window is closed and the minimum ventilation mode, using a mechanical ventilator, is enabled. In addition, window operation based on the indoor and outdoor temperatures is considered. A comfortable indoor temperature is assumed to be between 20 and $26^{\circ} \mathrm{C}$. As part for DWS, when the outdoor temperature is between 15 and $20^{\circ} \mathrm{C}$, that is, slightly cooler than the comfortable indoor temperature range, the appropriate ventilation mode is implemented. On the other hand, when the outdoor temperature is in the range of $20-25^{\circ} \mathrm{C}$, maximum ventilation is implemented. If the outdoor temperature is too cold $\left(<15^{\circ} \mathrm{C}\right)$ or too hot $\left(>25^{\circ} \mathrm{C}\right)$, natural ventilation is stopped by closing external and internal windows and minimum ventilation is implemented. Therefore, in addition to the window operation by 
the outdoor wind speed, window operation by the outdoor and indoor temperature is performed. During the natural ventilation period, external window is fully opened and the operable area of internal window is controlled according to the outdoor and indoor temperature condition. The operable area of internal window of DWS during appropriate ventilation mode is $0.60 \mathrm{~m}^{2}$. When the indoor and outdoor temperature conditions change to suitable for maximum ventilation mode, operable area of internal window of DWS increased to $1.28 \mathrm{~m}^{2}$ by changing window opening status. If the indoor temperature exceeds $26^{\circ} \mathrm{C}$ during the maximum ventilation mode or decreases to $20^{\circ} \mathrm{C}$ below, natural ventilation is stopped and minimum ventilation is performed. To enable this operation, the highest or lowest room temperature among the room temperatures of the residential unit is used as the representative room temperature that determines window condition. Figure 9 depicts the conceptual natural ventilation strategy and window operation modes of DWS. Figure 10 show the window settings and natural ventilation patterns of all window systems used in the study. The operable areas of SW and DW are not controllable. The operable areas of these two systems maintained to $0.62 \mathrm{~m}^{2}$ natural ventilation periods when outdoor temperature is in the range of $15-25^{\circ} \mathrm{C}$ and indoor temperature is in the range of $20-26^{\circ} \mathrm{C}$. Figure 11 illustrates the natural ventilation pattern in a residential unit. Doors between the rooms act like a passages for the natural ventilation.

Figure 9. Natural ventilation strategy and window operation modes.

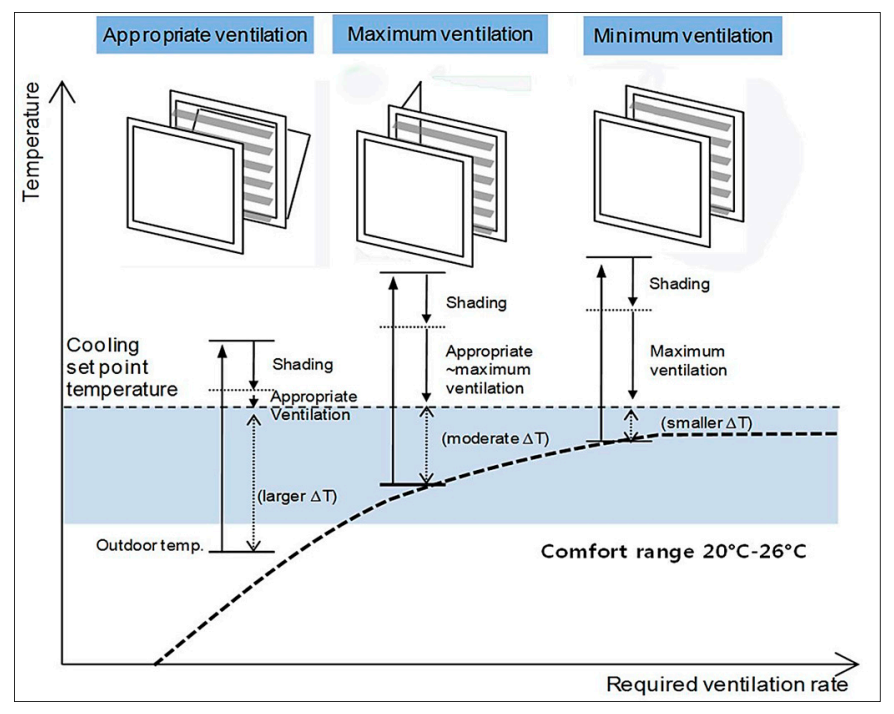

Figure 10. Window settings and natural ventilation patterns.

\begin{tabular}{|c|c|c|c|c|c|}
\hline Types & SW & DW & DWS - Appropriate ventilation & DWS - Maximum ventilation \\
\hline & Outdoor & Indoor & Outdoor & Indoor & Indoor \\
$\begin{array}{c}\text { Window } \\
\text { settings }\end{array}$ & & & & \\
\hline External window & Project window & Project window & Parallel window & Parallel window \\
\hline Internal window & - & Sliding window : fully opened & Tilt\& Turn window (Tilted ) & Tilt\& Turn window (Tilted ) \\
\hline
\end{tabular}


Figure 11. Natural ventilation patterns in residential unit.

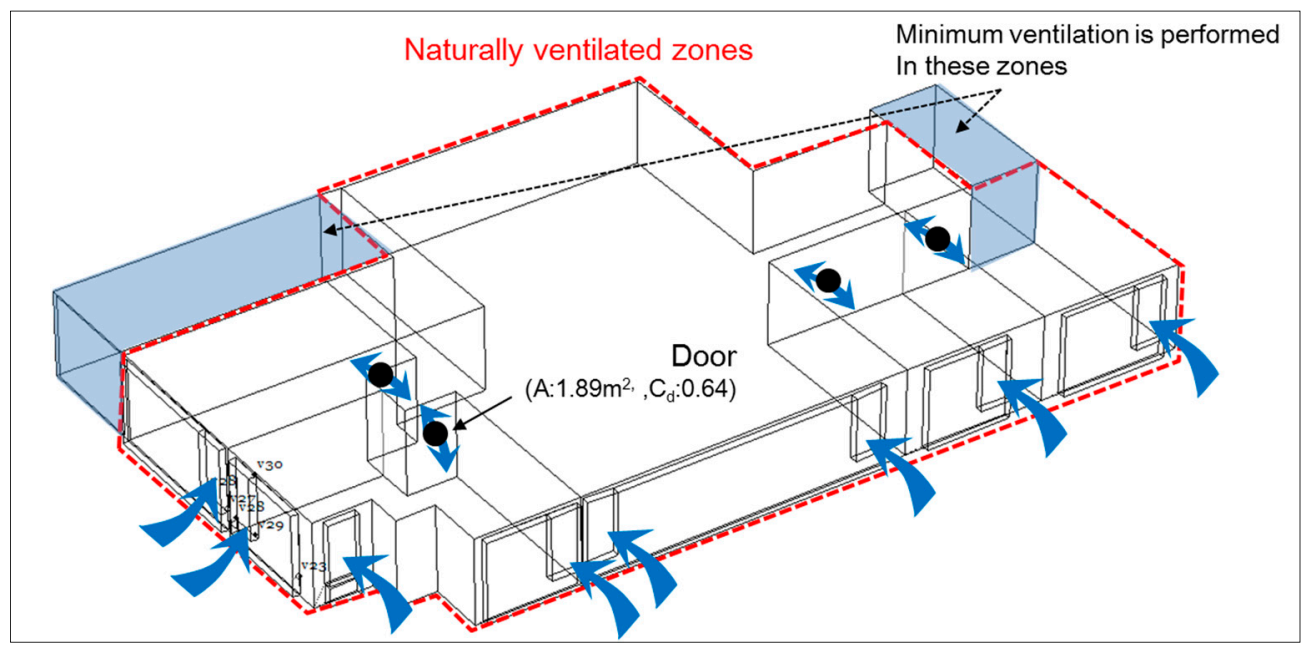

\subsection{Results and Discussion}

\subsubsection{Cooling Loads}

Tables 6 and 7 list the calculated cooling energy consumptions. The DW provides a limited cooling load reduction effect of about $7 \%-17 \%$ in comparison with a conventional SW. However, the DWS exhibits a better cooling load reduction performance. When the DWS is implemented, the cooling load is reduced by $39 \%-43 \%$ in the minimum ventilation mode, and by $57 \%-61 \%$ in the natural ventilation mode. These results demonstrate the effectiveness of DWS with regard to cooling load reduction in highly glazed residential buildings. When the natural ventilation is implemented to SW, DW, DWS-1 and DWS-2, cooling loads were reduced by $36 \%, 44 \%, 55 \%$ and $56 \%$, respectively. The efficiency of the natural ventilation increased as the SW changed to DW and DWSs. According to the simulation results, the implementation of an absorptive rear surface of the shading device in the DWS further reduces the required amount of cooling energy slightly. This approach realized a further $4 \%$ cooling load reduction in both the minimum and natural ventilation modes. Table 8 shows that the total number of hours in which cooling load occurred are reduced if natural ventilation is incorporated within the control pattern. The averaged natural ventilation rates of indoor space in $\mathrm{ACH}$ are demonstrated in Table 9. The operation of the window system in energy simulation is performed optimally and the effects of appropriate and maximum ventilation modes of DWS are hard to figure out. The data of Table 9 the natural ventilation rate changed properly in the energy simulation to exhaust the excessive internal heat and maintain indoor temperature within a comfort range. Three times higher natural ventilation rates are required during the maximum natural ventilation mode than the natural ventilation rates during the minimum ventilation mode. These values are 18.1-19.3 times higher than the minimum ventilation rate performed by mechanical ventilator. Pasquay shows the natural ventilation rate of Siemens building and RWE tower with DSF as 2-6 ACH and 2-12 ACH, respectively [30]. The natural ventilation rate of Siemens building is determined in the condition of tilted window (inward) without cross ventilation. This is the same condition of internal window of DWS. Considering the results of the previous study, it is turned out that the natural ventilation rates of this study covers from lower value to slightly higher value 
by the window control. The results show explicitly the usefulness of natural ventilation in cooling load reduction and improvement of its effectiveness with the DWS.

Table 6. Estimated monthly cooling loads.

\begin{tabular}{|c|c|c|c|c|c|c|c|c|}
\hline \multirow[t]{2}{*}{ Category } & \multicolumn{4}{|c|}{$\begin{array}{c}\text { Minimum ventilation mode } \\
(\mathrm{kWh})\end{array}$} & \multicolumn{4}{|c|}{$\begin{array}{c}\text { Natural ventilation }+ \text { Minimum ventilation mode } \\
\qquad(\mathrm{kWh})\end{array}$} \\
\hline & SW & DW & DWS-1 & DWS-2 & SW & DW & DWS-1 & DWS-2 \\
\hline May & 180 & 144 & 24 & 17 & 50 & 28 & 0 & 0 \\
\hline June & 686 & 676 & 438 & 396 & 377 & 292 & 121 & 103 \\
\hline July & 989 & 956 & 802 & 763 & 624 & 546 & 397 & 366 \\
\hline August & 1313 & 1223 & 1006 & 970 & 1001 & 886 & 613 & 577 \\
\hline September & 905 & 835 & 387 & 359 & 511 & 378 & 75 & 65 \\
\hline October & 453 & 382 & 83 & 77 & 315 & 251 & 22 & 19 \\
\hline Total & 4527 & 4215 & 2739 & 2582 & 2879 & 2380 & 1228 & 1130 \\
\hline
\end{tabular}

Table 7. Cooling load comparison among the simulation cases.

\begin{tabular}{clcccc}
\hline & Categories & SW & DW & DWS-1 & DWS-2 \\
\hline & Minimum ventilation mode & 4523 & 4215 & 2739 & 2582 \\
$\begin{array}{c}\text { Cooling load } \\
(\mathrm{kWh})\end{array}$ & Reductions (\%) & - & $7 \%$ & $39 \%$ & $43 \%$ \\
& $\begin{array}{l}\text { Minimum ventilation + } \\
\text { Natural ventilation mode }\end{array}$ & 2879 & 2380 & 1228 & 1130 \\
& Reductions (\%) & - & $17 \%$ & $57 \%$ & $61 \%$ \\
\hline \multicolumn{2}{c}{ Reductions by ventilation modes (\%) } & $36 \%$ & $44 \%$ & $55 \%$ & $56 \%$ \\
\hline
\end{tabular}

Table 8. Gross number of hours when the cooling load is occurred (in hours).

\begin{tabular}{ccc}
\hline Window types & Minimum ventilation mode & $\begin{array}{c}\text { Natural ventilation +Minimum } \\
\text { ventilation mode }\end{array}$ \\
\hline SW & 2911 & 1677 \\
DW & 3295 & 1882 \\
DWS-1 & 3030 & 1367 \\
DWS-2 & 2959 & 1299 \\
\hline
\end{tabular}

Table 9. Natural ventilation rates (in $\mathrm{ACH}$ ).

\begin{tabular}{ccc}
\hline \multirow{2}{*}{ Window types } & \multicolumn{2}{c}{ Outdoor temperature } \\
\cline { 2 - 3 } & $\mathbf{1 5 - 2 0}{ }^{\circ} \mathbf{C}$ & $\mathbf{2 0}-\mathbf{2 5}{ }^{\circ} \mathbf{C}$ \\
\hline SW & 4.1 & 12.7 \\
DW & 4.2 & 12.7 \\
DWS-1 & 4.4 & 13.5 \\
DWS-2 & 4.4 & 13.5 \\
\hline
\end{tabular}

Figure 12 and Table 10 present the heat transfer pattern and the net heat gain of indoor space through a window system incorporating shading devices during the entire cooling period. When the DWS is applied, all types of heat transmission are reduced. In particular, radiant and convective heat 
transmissions are significantly reduced. Solar transmitted relates to the glazing property and shading device. The DWS has a shading device in the cavity space that reflects the solar radiation and relieves the heat stress at the inner window system. This behavior reduces heat transfer into the indoor space by natural convection and radiation. When the absorptive rear surface of the shading device in the DWS is implemented, solar transmission is reduced further, whereas other heat transmission is slightly increased.

Figure 12. Heat transmitting pattern of a DWS.

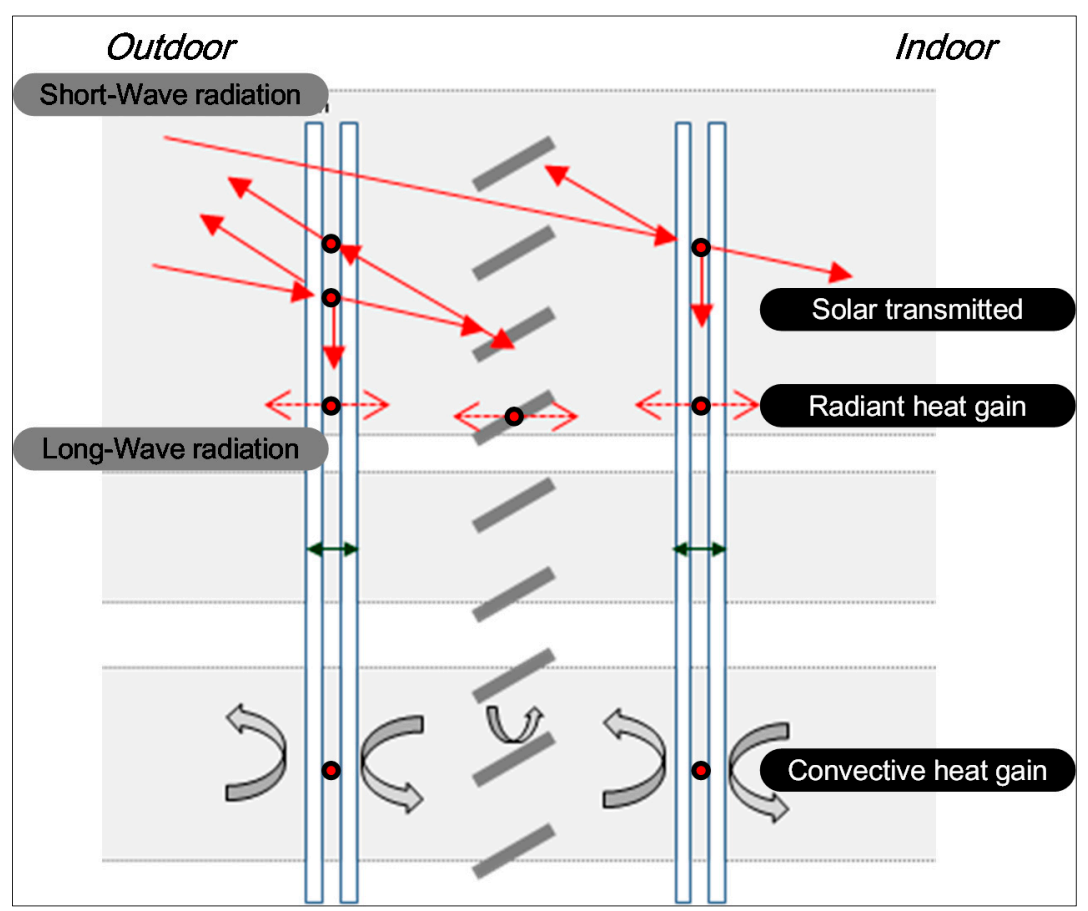

Table 10. Net heat flow to indoor space through a window when the cooling load occurs $(\mathrm{kWh})$.

\begin{tabular}{cccccc}
\hline \multicolumn{2}{c}{ Category } & SW & DW & DWS-1 & DWS-2 \\
\hline \multirow{3}{*}{ Minimum ventilation mode } & Radiant heat gain & 3000 & 2085 & 243 & 284 \\
& Convective heat gain & 3337 & 2515 & 936 & 1035 \\
& Solar transmitted & 1282 & 1731 & 867 & 490 \\
\hline \multirow{2}{*}{ Natural ventilation +} & Radiant heat gain & 3057 & 1504 & 160 & 168 \\
Minimum ventilation mode & Convective heat gain & 2984 & 2693 & 527 & 538 \\
& Solar transmitted & 1050 & 137 & 499 & 278 \\
\hline
\end{tabular}

\subsubsection{Electricity Cost}

Electricity energy costs are evaluated based upon the cooling-load results. The calculated cooling load is inverted to electrical energy by using the COP of the PAC. The COP of the PAC is assumed to 3.0. Monthly electricity consumption is obtained by adding the calculated cooling energy and the measured monthly base electricity consumption of the target building, $583 \mathrm{kWh}$. The calculation method is stated in Equation (4), and the estimated monthly electricity consumption is described in Table 12. Electricity cost is derived from the pricing method of the Korean Electric Power Corporation [31], which is the electricity supplier in Korea. Tables 11 and 12 show the monthly estimated electricity consumption and energy costs during the cooling period from May to October. Electricity cost reduction is brought about via the 
application of the DWS instead of an SW. About $20 \%-24 \%$ of electricity cost is reduced by the implementation of the DWS. The DW exhibits limited effects of 3\%-7\% in electricity cost reduction.

Monthly electricity consumption

$$
=\frac{\text { Cooling load }}{\text { COP of PAC }}+\text { Monthly base electricity consumption }
$$

Table 11. Estimated monthly electricity consumption.

\begin{tabular}{ccccccccc}
\hline \multirow{2}{*}{ Category } & \multicolumn{6}{c}{ Minimum ventilation (kWh) } & \multicolumn{5}{c}{ Natural ventilation + Minimum ventilation mode (kWh) } \\
\cline { 2 - 8 } & SW & DW & DWS-1 & DWS-2 & SW & DW & DWS-1 & DWS-2 \\
\hline May & 643 & 631 & 591 & 589 & 600 & 592 & 583 & 583 \\
June & 812 & 808 & 729 & 715 & 709 & 680 & 623 & 617 \\
July & 913 & 902 & 850 & 837 & 791 & 765 & 715 & 705 \\
August & 1021 & 991 & 918 & 906 & 917 & 878 & 787 & 775 \\
September & 885 & 861 & 712 & 703 & 753 & 709 & 608 & 605 \\
October & 734 & 710 & 611 & 609 & 688 & 667 & 590 & 589 \\
Total & 5007 & 4903 & 4411 & 4359 & 4458 & 4291 & 3907 & 3875 \\
\hline
\end{tabular}

Table 12. Estimated electricity cost.

\begin{tabular}{|c|c|c|c|c|c|c|c|c|}
\hline \multirow{2}{*}{ Category } & \multicolumn{4}{|c|}{ Minimum ventilation (Won) } & \multicolumn{4}{|c|}{ Natural ventilation + Minimum ventilation mode (Won) } \\
\hline & SW & DW & DWS-1 & DWS-2 & SW & DW & DWS-1 & DWS-2 \\
\hline May & 252,040 & 242,360 & 210,090 & 208,480 & 217,350 & 210,900 & 203,630 & 203,630 \\
\hline June & 388,370 & 385,150 & 321,410 & 310,120 & 305,280 & 281,890 & 235,900 & 231,060 \\
\hline July & 469,840 & 460,980 & 419,030 & 408,540 & 371,430 & 350,460 & 310,120 & 302,050 \\
\hline August & 556,970 & 553,770 & 473,890 & 464,200 & 473,070 & 441,620 & 368,210 & 358,520 \\
\hline September & 447,260 & 427,900 & 307,700 & 300,440 & 340,770 & 305,280 & 223,810 & 221,380 \\
\hline October & 325,450 & 306,090 & 226,230 & 224,610 & 288,340 & 271,400 & 209,290 & 208,480 \\
\hline $\begin{array}{l}\text { Total } \\
\text { (Won) }\end{array}$ & $2,439,930$ & $2,376,250$ & $1,958,350$ & $1,916,390$ & $1,996,240$ & $1,861,550$ & $1,550,960$ & $1,525,120$ \\
\hline (US Dollar) & 2360 & 2298 & 1894 & 1853 & 1931 & 1800 & 1500 & 1475 \\
\hline $\begin{array}{l}\text { Reduction } \\
(\%)\end{array}$ & - & $3 \%$ & $20 \%$ & $21 \%$ & - & $7 \%$ & $22 \%$ & $24 \%$ \\
\hline
\end{tabular}

\section{Daylight Simulations}

\subsection{Daylighting Simulation Overview}

The daylighting factor (DF) and illuminance distributions of the living room, with each window with and without the shading device being implemented, are evaluated. The resolution of the sensor grid for illuminance evaluation is set to $0.2 \times 0.2 \mathrm{~m}$. The height of the sensor grid is set to $0.7 \mathrm{~m}$ above the floor. The living room is divided into three parts: a perimeter zone ( $\sim 3.6 \mathrm{~m}$ from window), a middle zone (3.6$7.2 \mathrm{~m}$ from window), and an internal zone (7.2-14.2 $\mathrm{m}$ from window). The depth of the perimeter zone and the middle zone is 1.5 times higher than the room height from floor to ceiling. Figure 13 illustrates the sensor grid image and the three zones of the living room. The target space material is represented in Table 13. DF is calculated under an overcast sky. 
Figure 13. Sensor grid and zoning.

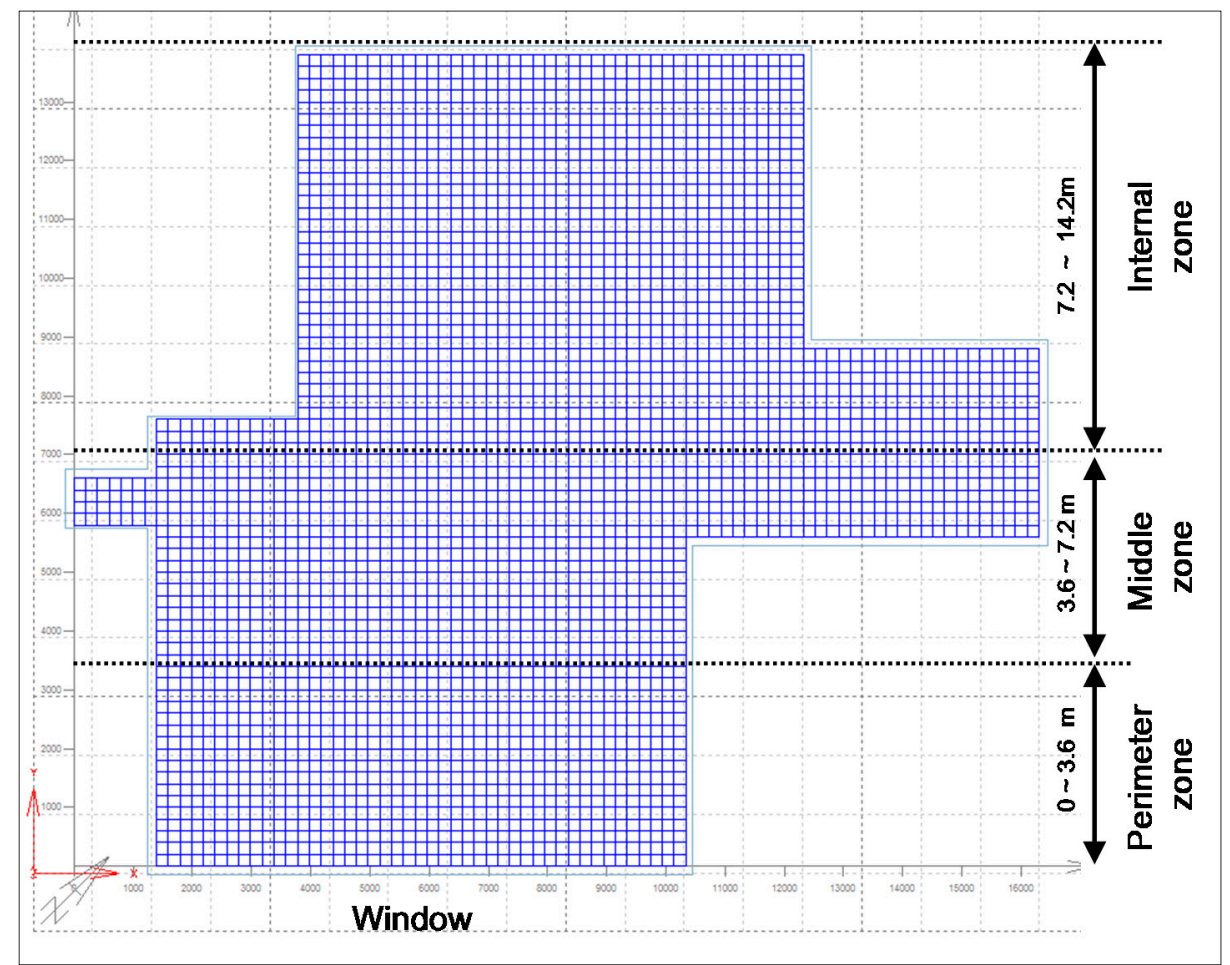

Table 13. Daylighting simulation variables.

\begin{tabular}{ccc}
\hline \multicolumn{2}{c}{ Building components } & Reflectance \\
\hline Wall & & 0.604 \\
Floor & & 0.299 \\
Ceiling & & 0.702 \\
Window frame & & 0.796 \\
Glazing property & External window & 0.639 \\
(Visual transmittance) & Internal window & 0.611 \\
Room size & Depth & $14.2 \mathrm{~m}$ \\
& Height & $2.4 \mathrm{~m}$ \\
Cavity depth & DW & $5 \mathrm{~cm}$ \\
& DWS & $20 \mathrm{~cm}$ \\
Simulation time & (for illuminance) & $21 \mathrm{June}(12: 00 \mathrm{pm})$ \\
\hline
\end{tabular}

\subsection{Results and Discussion}

\subsubsection{Daylighting Factor}

Table 14 describes the evaluated daylighting factor. The DF in the living room is very low when the shading device is implemented in DW and DWS. The ratios of the sensor grid when the DF exceeds 2 are only $0.8 \%, 0 \%$, and $0 \%$ for DW, DWS-1, and DWS-2, respectively, with a shading device. In this study, the shading device is set to $45^{\circ}$ to reflect solar radiation outward effectively in order to reduce the cooling load increase due to the excessive solar heat gain. The results of the DF simulation show that double-layered window systems, such as DW and DWS, may result in an inappropriate visual environment during the cooling period with this kind of shading device setting. 
Table 14. Daylighting factor.

\begin{tabular}{cccccccc}
\hline Shading condition & \multicolumn{3}{c}{ Without shading } & \multicolumn{4}{c}{ With shading } \\
\hline Window type & SW & DW & DWS & SW & DW & DWS-1 & DWS-2 \\
$\quad$ Reflectivity & - & - & - & $84 / 84$ & $84 / 84$ & $84 / 84$ & $84 / 10$ \\
(Outward/Inward) & & & & & & & 0.6 \\
$\quad$ Average & 2.8 & 1.7 & 1.6 & 0.8 & 0.6 & 0.4 \\
Ration of DF $>2$ & $29.1 \%$ & $20.3 \%$ & $19.7 \%$ & $7.6 \%$ & $0.8 \%$ & $0.0 \%$ & $0.0 \%$ \\
\hline
\end{tabular}

The DF does not reflect the effects due to location, building orientation [32], and indoor illuminance level on the summer solstice (these effects were evaluated separately). Figures 14 and 15 illustrate the illuminance distributions in the living room without and with a shading device, respectively, on the summer solstice. In addition, the average illuminance level of each indoor zone is described in Table 15. It turns out that daylight does not affect the level of illuminance of the internal zone. The illuminance levels of the three cases without a shading device at this zone were maintained below $100 \mathrm{~lx}$. In this condition, abundant daylight existed in the perimeter zone and the middle zone. The average illuminance levels of these zones exceed 200 lx. In particular, there is an excessive amount of daylight in the perimeter zone implementing a SW without a shading device, and the average illuminance of this zone reaches 2293 1x. Implementation of DW or DWS reduces the excessive illuminance level of the perimeter zone while maintaining the illuminance level of the middle zone at a satisfactory level for the occupants. The implementation of a tilted shading device set to $45^{\circ}$ reduced the indoor illuminance level significantly. When the shading device with a high reflectivity of $84 \%$ at both surfaces is implemented in a SW, DW, and DWS, the illuminance level of the perimeter zone is reduced by $75.7 \%, 72.7 \%$, and $71.9 \%$, respectively. Under these conditions, the average illuminance level of each perimeter zone was maintained over 200 lx. However, the illuminance levels at the middle zone and the internal zone are below 100 lx and may result in an inappropriate visual environment. According to the simulation results, DW and DWS with the same shading conditions do not show a significant difference with respect to illuminance level. The shading device with a low reflective surface facing the indoor space resulted in a drastically reduced illuminance level. The illuminance levels of all zones are under $200 \mathrm{~lx}$ and can cause visual discomfort for occupants. As with the illuminance distribution of windows without a shading device, the internal zone is thought to be inappropriate for daylighting, and the availability of natural lighting in the perimeter zone and the middle zone is considerable. If occupants tilt all reflective shading devices to $45^{\circ}$ to reduce the effective cooling load, daylighting availability is restricted in the middle zone at first. Even though DWS shows the lowest illuminance level, the illuminance level at the perimeter zone is acceptable in this condition. However, a reduction in reflectivity of the internal surface of the shading device results in an undesirable visual environment. This kind of application can be used for maximum cooling load reduction when the crucial activities of the occupants do not occur or the occupants are absent. Considering the simulation results, the DWS with a reflective shading device at all surfaces is more appropriate for effective cooling load reduction and visual comfort. 
Table 15. Average illumination level (by lux).

\begin{tabular}{cccccccc}
\hline Shading condition & \multicolumn{3}{c}{ Without shading } & \multicolumn{4}{c}{ With shading } \\
\hline Window type & SW & DW & DWS & SW & DW & DWS-1 & DWS-2 \\
Reflectivity & & & & & & & \\
(Outward/Inward) & - & - & - & $84 / 84$ & $84 / 84$ & $84 / 84$ & $84 / 10$ \\
Perimeter zone & 2293.52 & 1045.31 & 999.99 & 557.51 & 285.53 & 280.57 & 159.49 \\
Middle zone & 374.31 & 209.85 & 209.63 & 82.67 & 42.02 & 42.80 & 21.88 \\
Internal zone & 105.08 & 59.03 & 59.03 & 15.83 & 7.88 & 8.70 & 2.82 \\
\hline
\end{tabular}

Figure 14. Illuminance distribution in the living room without a shading device.

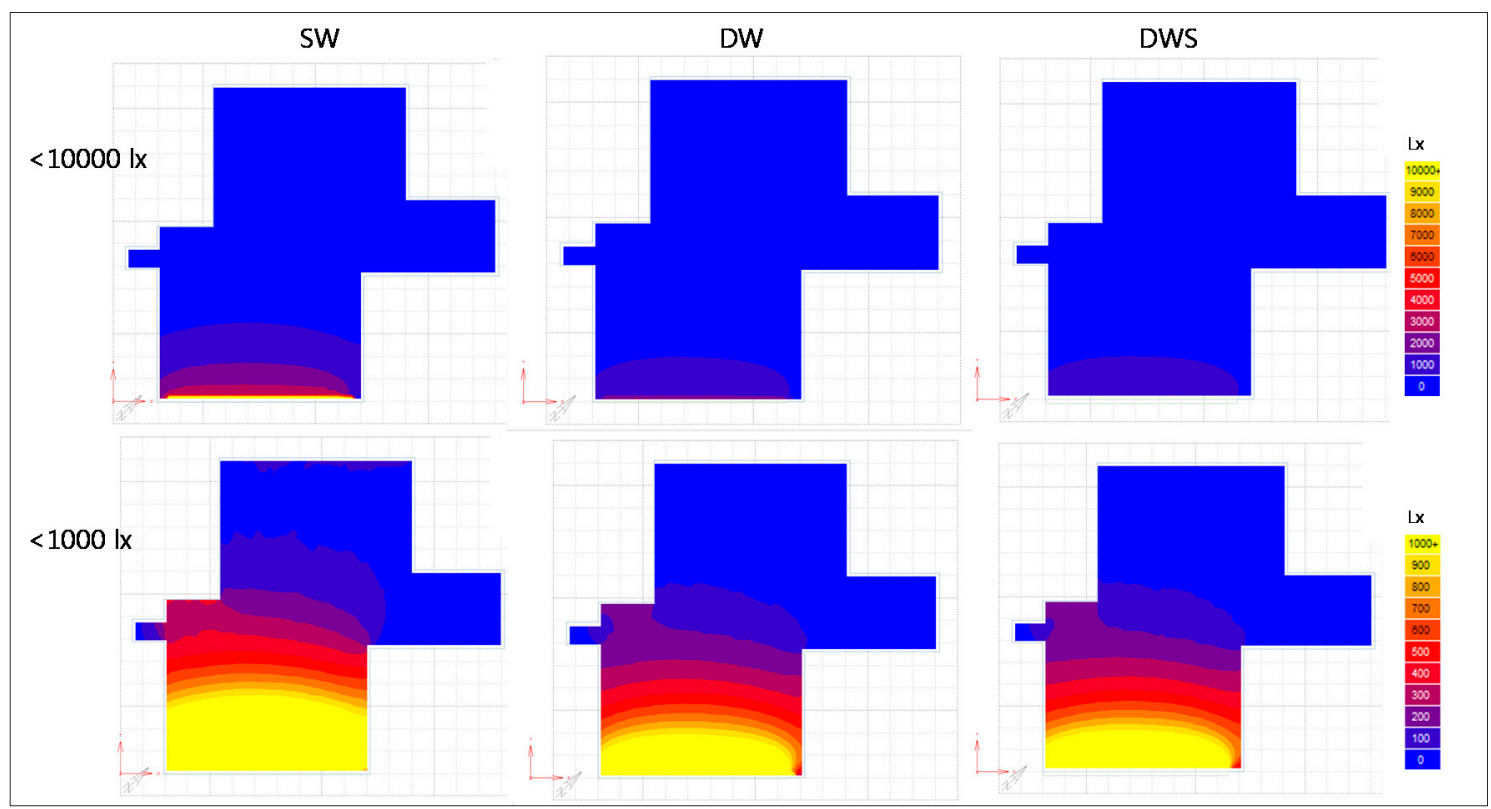

Figure 15. Illuminance (in lux) distribution in the living room with a tilted shading device.

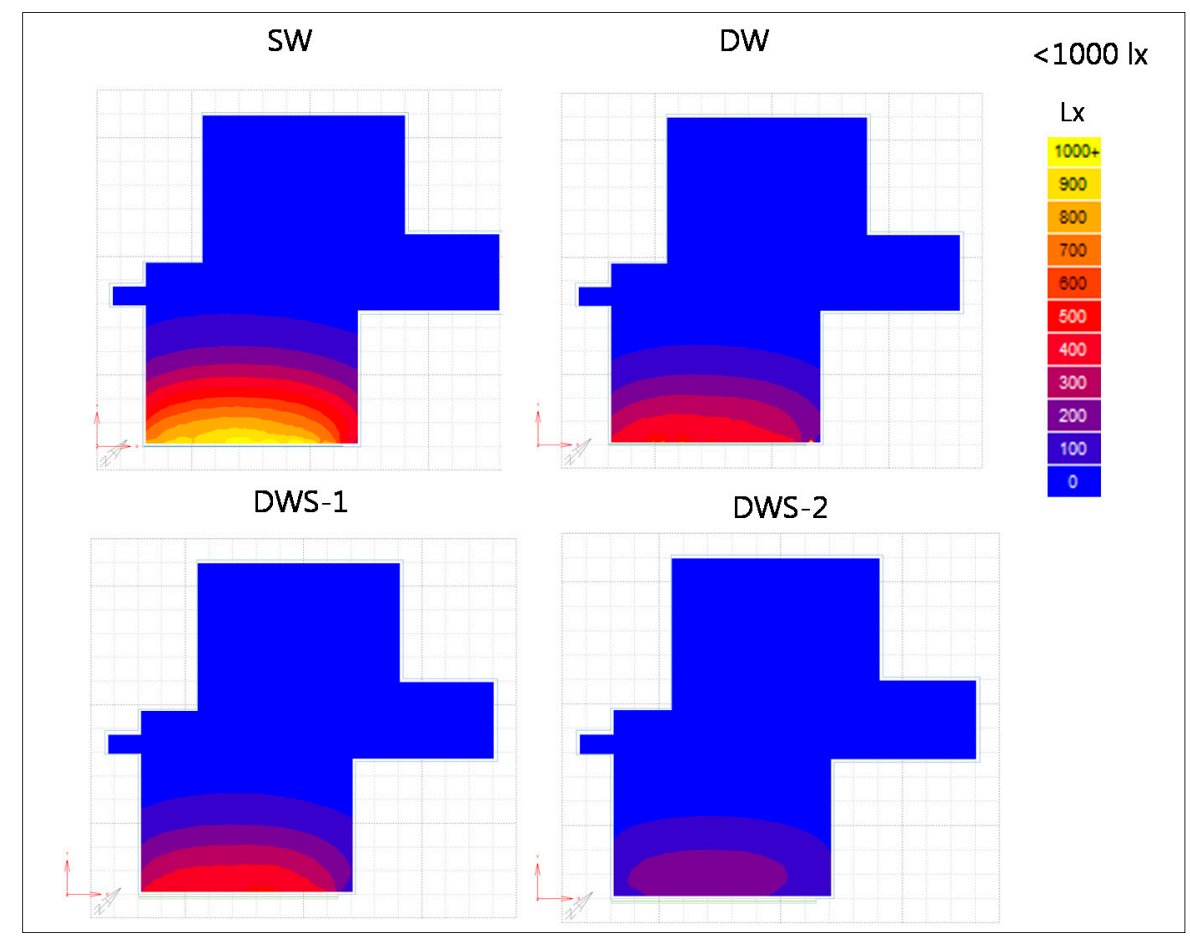




\subsubsection{Useful Daylight Index (UDI)}

UDI indicates the annual occurrence of illuminance level useful to occupants. It can be evaluate as useful daylight, when the illuminance levels are between 100 and 2000 1x. Table 16 shows the UDI values evaluated by DAYSIM and ECOTECT. According to the simulation results, $\mathrm{UDI}_{<100}$ is $100 \%$ in every case. These results show that the target space with deep floor plan is under-lit space regardless of window system types and their shading device settings.

Table 16. Evaluated UDI values in living room (in percentage).

\begin{tabular}{cccccccc}
\hline Shading condition & \multicolumn{3}{c}{ Without shading } & \multicolumn{4}{c}{ With shading } \\
\hline Window type & SW & DW & DWS & SW & DW & DWS-1 & DWS-2 \\
Reflectivity & - & - & - & $84 / 84$ & $84 / 84$ & $84 / 84$ & $84 / 10$ \\
(Outward/Inward) & & & & & & & 100 \\
UDI $<100$ & 100 & 100 & 100 & 100 & 100 & 100 & 100 \\
$\mathrm{UDI}_{100-2000}$ & 0 & 0 & 0 & 0 & 0 & 0 & 0 \\
$\mathrm{UDI}_{>2000}$ & 0 & 0 & 0 & 0 & 0 & 0 & 0 \\
\hline
\end{tabular}

\subsubsection{Absolute Glare}

Assessment on the absolute glare used the NUTEK guideline. Detailed threshold values are described in Table 17.

Table 17. Threshold levels of absolute glare.

\begin{tabular}{|c|c|c|c|c|}
\hline Range & $>2000 \mathrm{~cd} / \mathrm{m}^{2}$ & $>1000 \mathrm{~cd} / \mathrm{m}^{2}$ & $<500 \mathrm{~cd} / \mathrm{m}^{2}$ & $<30 \mathrm{~cd} / \mathrm{m}^{2}$ \\
\hline Perception of occupants & $\begin{array}{c}\text { Too bright, } \\
\text { anywhere in the room }\end{array}$ & $\begin{array}{c}\text { Too bright, } \\
\text { in the visual field }\end{array}$ & Preferable & Unacceptably dark \\
\hline
\end{tabular}

Figure 16 illustrates the absolute glare distribution around each window system. Without shading device, there is much light that exceeds $2000 \mathrm{~cd} / \mathrm{m}^{2}$ at the surface of SW and adjacent walls, ceiling and floor. Thus, high probability of glare is predicted. In this situation, implementation of DW and DWS can slightly mitigate the luminance level at the window surface and adjacent surfaces. However, the luminance values at large area of window glazing surface still exceeds $1000 \mathrm{~cd} / \mathrm{m}^{2}$ and the risk of glare remains. On the other hand, tilted shading device that can reflect solar ray outwardly reduces luminance level drastically. Shading device implemented to SW with reflective surfaces at front side and rear side of slats maintained luminance level of lighting source at preferable or slightly bright condition. When this shading device is implemented to DW and DWS, luminance levels meet preferable condition. The implementation of shading device with asymmetric reflectance decreased the luminance level of glazing surface to unacceptably dark status in all window types. These results support the application of shading device with high reflectivity at all surface is more appropriate for the comfortable visual environment in the target space. The rendered images and sampled luminance levels are depicted in Figure 17. 
Figure 16. False color images of absolute glare distribution in the living room (exposure: 1.0).

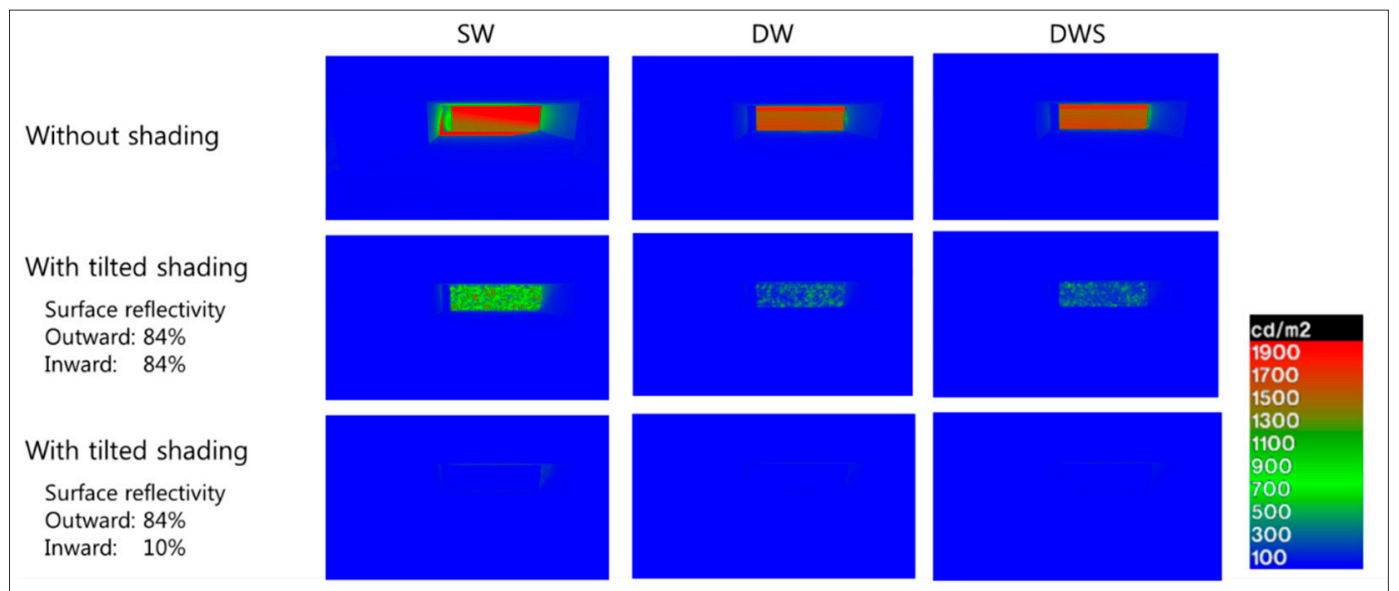

Figure 17. Absolute glare at window surface with shading devices (exposure: 1.0).

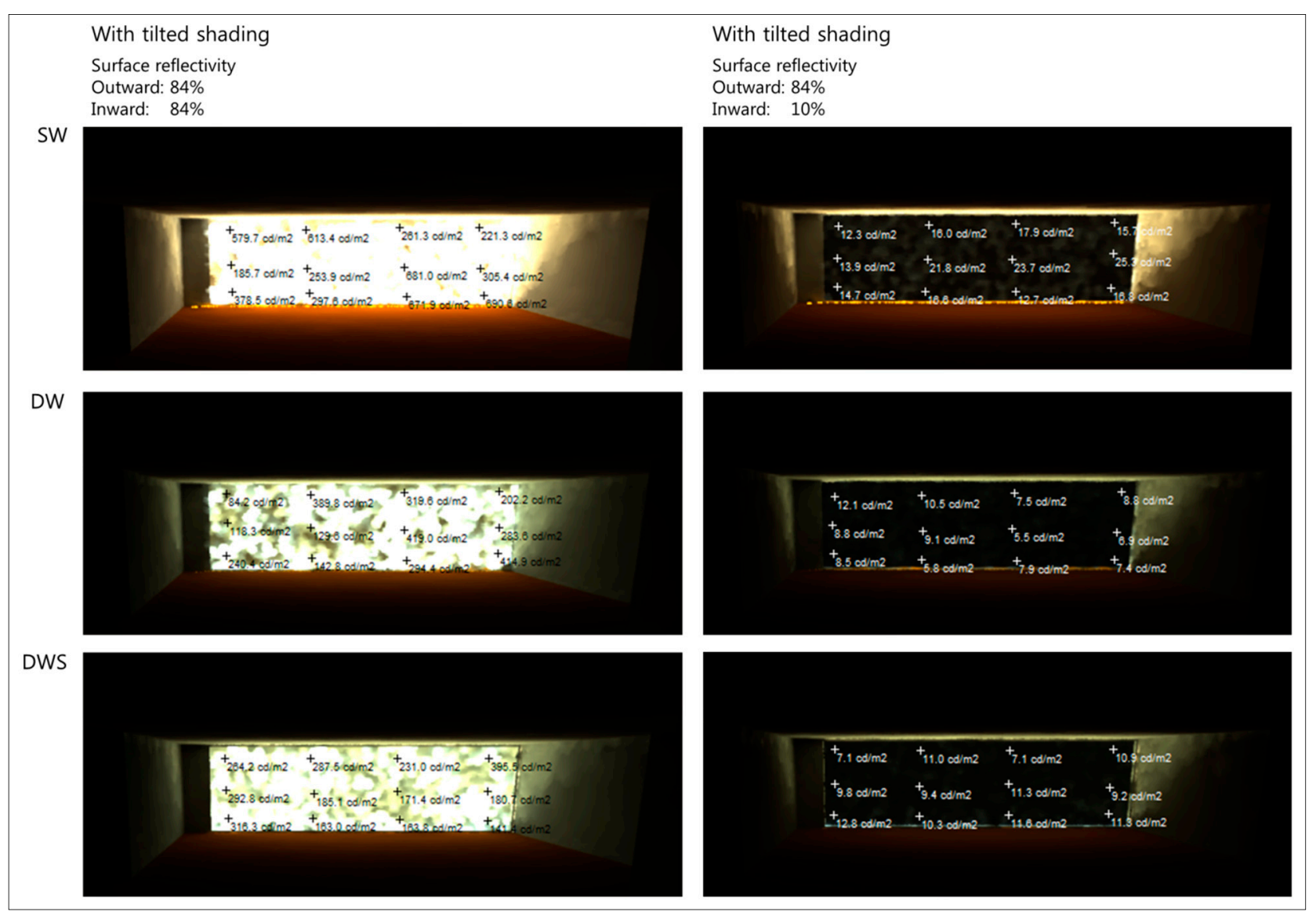

\section{Conclusions}

This study evaluated the cooling energy reduction and visual environment brought about by the implementation of a DWS in a highly glazed residential building. An energy simulation model was verified via a comparison with measured data and actual energy consumption data. A comparative case study was undertaken to investigate the performance of the DWS. Visual environment is evaluated by using simulation tools: Radiance, Daysim and Ecotect. The major results can be summarized as follows: 
(1) According to our results, a cooling load reduction can be achieved by adopting the DWS. This reduction ranges from $43 \%$ to $61 \%$. Regardless of the implementation of natural ventilation, the DWS offers a better performance than conventional windows. With natural ventilation, the performance of the DWS can be maximized.

(2) The convective and radiant heat reductions were the most critical factors affecting the reduction of the cooling load via the application of the DWS.

(3) An increase in the solar absorption by the rear surface of the shading device can reduce the cooling load by approximately $4 \%$. This option could be considered when the cooling load has to be reduced to the lowest possible level.

(4) Electricity cost during the cooling period can be significantly reduced by about $20 \%-24 \%$ by replacing conventional SWs with a DWS.

(5) A shading device setting that prioritizes effective cooling load reduction can greatly decrease the DF and the glare risk of the indoor space. Especially, implementation of a shading device with low reflectivity at rear surface can result in undesirable low luminance level and illuminance level at indoor space.

(6) A DWS implementing shading device with highly reflective at all surfaces is appropriate option for the better thermal and visual environment, while shading device with low reflectivity at the rear surface can contribute an additional 4\% cooling load reduction.

In terms of cooling energy reduction, electricity cost reduction, visual comfort and appropriate settings of the shading device of a DWS in highly glazed residential buildings in Korea are identified in this study.

\section{Acknowledgments}

This research was supported by a grant (11 High-tech Urban G03) from the High-tech Urban Development Program funded by the Ministry of Land Infrastructure and Transport of the Korean government, and a research assistance program of Gyeongnam National University of Science and Technology.

\section{Author Contributions}

Chang Heon Cheong is the designer of the research work and contributed to the simulation and the writing of the paper. Taeyeon Kim contributed to the analysis and to the writing of the paper. Seung-Bok Leigh is the coordinator of the research group and contributed to the design of the DWS.

\section{Conflicts of Interest}

The authors declare no conflict of interest.

\section{References}

1. Da Silva, F.M.; Gomes, M.G. Gap inner pressures in multistory double skin facades. Energ. Build. 2008, 40, 1553-1559.

2. Roth, K.; Lawrence, T.; Brodrick, J. Double skin facade. ASHRAE J. 2007, 49, 70-73. 
3. Safer, N.; Woloszyn, M.; Roux, J.-J. Three-dimensional simulation with a CFD tool of the airflow phenomena in single floor double-skin facade equipped with a Venetian blind. Solar Energ. 2005, 79, 193-203.

4. Hamza, N. Double versus single skin facades in hot arid areas. Energ. Buildings 2008, 40, 240-248.

5. Baldinelli, G. Double skin facades for warm climate regions: Analysis of a solution with an integrated movable shading system. Build. Environ. 2009, 44, 1107-1118.

6. Kim, S.Y.; Song, K.D. Determining photosensor conditions of a daylight dimming control system using different double-skin envelope configurations. Indoor Build. Environ. 2007, 16, 411-425.

7. Ghaffarian, H.A.; Beradi, U.; Makaremi, N. Intelligent facades in low-energy buildings. Br. $J$. Environ. Clim. Change 2012, 2, 437-464.

8. Fallahi, A.; Haghighat, F.; Elsadi, H. Energy performance assessment of double-skin facade with thermal mass. Energ. Build. 2010, 42, 1499-1509.

9. Zhou, J.; Chen, Y. A review on applying ventilated double-skin facade to buildings in hot-summer and cold-winter zone in China. Renew. Sustain. Energ. Rev. 2010, 14, 1321-1328.

10. Huckemann, V.; Kuchen, E.; Leão, M. Empirical thermal comfort evaluation of single and double skin facades. Build. Environ. 2010, 45, 976-982.

11. Yoo, S.; Jeong, H.; Ahn, B.L; Han, H.; Seo, D.; Lee, J.; Jang, C.Y. Thermal transmittance of window systems and effects on building heating energy use and energy efficiency ratings in South Korea. Energ. Build. 2013, 67, 236-244.

12. Joe, J.; Choi, W.; Kwon, H.; Huh, J.H. Load characteristics and operation strategies of building integrated with multi-story double skin façade. Energ. Build. 2013, 60, 185-198.

13. Gratia, E.; de Herde, A. Natural cooling strategies efficiency in an office building with a double-skin façade. Energ. Build. 2004, 36, 1139-1152.

14. Gratia, E.; de Herde, A. Guidelines for improving natural daytime ventilation in an office building with a double-skin façade. Solar Energ. 2007, 81, 435-448.

15. Gratia, E.; de Herde, A. Greenhouse effect in double-skin façade. Energ. Build. 2007, 39, 199-211.

16. Saelens, D.; Roels, S.; Hens, H. On the influence of the inlet temperature in multiple-skin facade modeling. In Proceedings of the 8th International IBPSA Conference, Eindhoven, The Netherlands, 11-14 August 2003; pp. 1139-1146.

17. Cho, J.-K.; Hong, M.-H.; Yoo, C.-W. A case study on curtain-wall and window types of high-rise residences in Korea for improvement of natural ventilation. J. Archit. Inst. Korea 2009, 25, 253-261.

18. Branislav, T. Buildings Envelopes Controlling Solar Radiation Gains. Available online: http://vts.su.ac.rs/docs/expres2012/01.\%20Todorovic\%20prof..pdf (accessed on 27 May 2014).

19. Nikoofard, S.; Ugursal, V.I.; Beausoleil-Morrison, I. Effect of external shading on household energy requirement for heating and cooling in Canada. Energ. Build. 2011, 43, 1627-1635.

20. Kim, J.T.; Kim, G. Advanced external shading device to maximize visual and view performance. Indoor Build Environ. 2010, 19, 65-72.

21. Roche, L. Summertime performance of an automated lighting and blinds control system. Lighting Res. Technol. 2002, 34, 11-25.

22. Laouadi, A.; Parekh, A. Complex fenestration systems: Towards product ratings for indoor environment quality. Lighting Res. Technol. 2007, 39, 109-122. 
23. Dubois, M.C. Impact of shading devices on daylight quality in offices: Simulation with radiance. Available online: https://lup.lub.lu.se/search/publication/526054 (accessed on 20 October 2014).

24. Laouadi, A.; Reinhart, C.F.; Bourgeois, D. Efficient calculation of daylight coefficients for rooms with dissimilar complex fenestration systems. J. Build. Perform. Simul. 2008, 1, 3-15.

25. Ochoa, C.E.; Aries, M.B.C.; Hensen, J.L.M. State of the art in lighting simulation for building science: A literature review. J. Build. Perform. Simul. 2012, 5, 209-233.

26. Lomanowski, B.A. Implementation of Window Shading Models into Dynamic Whole-building Simulation. Available online: https://uwspace.uwaterloo.ca/handle/10012/4164 (accessed on 12 December 2008).

27. Papakonstantinou, K.A.; Kiranoudis, C.T.; Markatos, N.C. Numerical simulation of air flow field in single-sided ventilated buildings. Energ. Build. 2000, 33, 41-48.

28. Prajongsan, P.; Sharples, P. Enhancing natural ventilation, thermal comfort and energy savings in high-rise residential buildings in Bangkok through the use of ventilation shafts. Build. Environ. 2012, 50, 104-113.

29. Cheong, C.-H.; Kim, T.-Y.; Leigh, S.-B.; Hwang, S.-H. Indoor Air Flow Pattern in the Mixed-Use Apartment with Double Window System. J. Archit. Inst. Korea 2013, 12, 287-296.

30. Pasquay, T. Natural ventilation in high-rise buildings with double facades, saving or waste of energy. Energ. Build. 2004, 36, 381-389.

31. Electricity Rates Calculator (in Korean). Available online: http://cyber.kepco.co.kr/ckepco/front/ jsp/CY/J/A/CYJAPP000.jsp (accessed on 20 October 2014).

32. Berardi, U.; Wang, T. Daylighting in an atrium-type high performance house. Build. Environ. 2014, 76, 92-104.

(C) 2014 by the authors; licensee MDPI, Basel, Switzerland. This article is an open access article distributed under the terms and conditions of the Creative Commons Attribution license (http://creativecommons.org/licenses/by/4.0/). 